\title{
"Institutional Effort": A Reality-Based Model for Assessment of Community College Productivity
}

\author{
CAROL PARKER THOMPSON \\ RICHARD L. ALFRED \\ MALCOLM LOWTHER
}

Reports issued by government agencies, and state and national associations, and individual colleges indicate that communitycolleges are currently experiencing new pressures for growth to meet the educational needs of diverse constituencies. These reports also indicate that concurrent with pressures for growth are counterpressures for efficiency through planning, program review and resource reallocation to provide maximum benefits within current resources. Largely an outgrowth of increased demands for institutional accountability, competing pressures for growth and efficiency present an uncomfortable dilemma to community colleges. Public two-year colleges fit Drucker's model of the service organization because of their need for slack in the operating budget to respond to constituency needs. When decision-makers add programs on the basis of current revenues, but fail to consider future resource requirements to operate the same or additional programs, they may create strain in the institutional budget, thereby reducing slack and limiting capacity for development of new programs and services.

Community colleges have two basic choices when seeking a solution to this dilemma. They can attempt to cut the costs associated with development of new programs and services or they can attempt to raise incremental revenues to offset rising costs. Requests for incremental revenues (local tax, tuition, and state aid) are apt to be more successful when there is evidence of institutional productivity that reflects the values and needs of important constituencies. To create impact, productivity assessment strategies must provide tangible evidence of performance based on objective measures that can be applied with some degree of precision to specific target groups.

This paper presents a new perspective on productivity assessment in community colleges. Borrowing from organizational constructs espoused by Drucker, community colleges are viewed as service organizations in which productivity is defined as the capacity for timely response to clients through services that satisfy 
needs. Responsiveness involves institutional effort in identifying constituency needs, allocating resources, developing programs and services, establishing policies, marketing services, and evaluating results. Colleges which provide evidence of "effort" in meeting constituency needs can be viewed as productive institutions to the extent that they provide benefits to clients through "cost-producing" programs and services which satisfy needs.

\section{Definition and Dimensions of Institutional Effort}

Current and prevailing notions of productivity in the literature are inappropriate for community colleges because they do not take into account contextual factors that are unique to community-based institutions. Factors such as graduation and attrition rates, student utilization of academic support services, and participation in campus activities are appropriate indices of productivity in four-year institutions where students live on campus and have extensive opportunities for participation in campus activities. They are not appropriate for community colleges where students commute to campus, hold jobs, and alter patterns of enrollment in accord with extra-campus conditions.

To surmount this contextual problem, alternative approaches to assessment of productivity are required. Building on concepts developed by Priest and Pickelman (1976) and Lenning (1978), productivity in community colleges can be defined in terms of the effort expended in various programs and policy contexts to provide services in response to constituency needs. Advancing this basic premise a step further, it is possible to define "effort" as:

A product or score resulting from the combined measurement of multiple variables describing community college performance in the development and provision of programs, policies and services that meet constituency needs. Effort is expressed as a measure of the discrepancy between "current" and "desired" levels of institutional performance in providing activities that meet constituency needs as judged by relevant observers using multiple criteria agreed upon in advance.

This definition combines concepts of "constituency needs," "current performance," "desired performance," and "discrepancy" in such a way that the amount of effort varies directly with the level of desired performance and inversely with the amount of discrepancy. Therefore, the greater the discrepancy between constituency needs for programs and services and the actual program and service offerings of the institution, the lower the effort score.

\section{Model for Measurement of "Effort"}

The literature on institutional effort is sparse and focuses primarily on the selection of measures to evaluate effort, excluding the assessment of effort itself (Shaw and Wright, 1967; Robinson and Sharer, 1969). There does not exist a model for assessment of community college effort, especially one using multiple criteria to arrive at a composite effort score; therefore, the key issue in model development is the use of consistent measures of effort, multiple objective criteria, and common indicators of outcome.

A frequently used measure of effort in community colleges is dollars spent on instruction. College administrators tend to be supportive of enrollment and income-generating activities, especially iristruction; however, program expenditures 
may not constitute an accurate measure of institutional effort. More precise effort indicators may be those factors that generate costs (e.g., student services and instructional support). The rationale for choosing cost-producing programs and services as a measure of effort is that cost involves a choice among alternatives, assessment of benefits, and, ultimately, difficult decisions regarding what the institution must provide (programs and services) and what it must spend in order to obtain resources (money and enrollment) from the constituencies it serves. Need-satisfying programs which involve costs are required if community colleges expect to attract new clientele and to maintain a positive image.

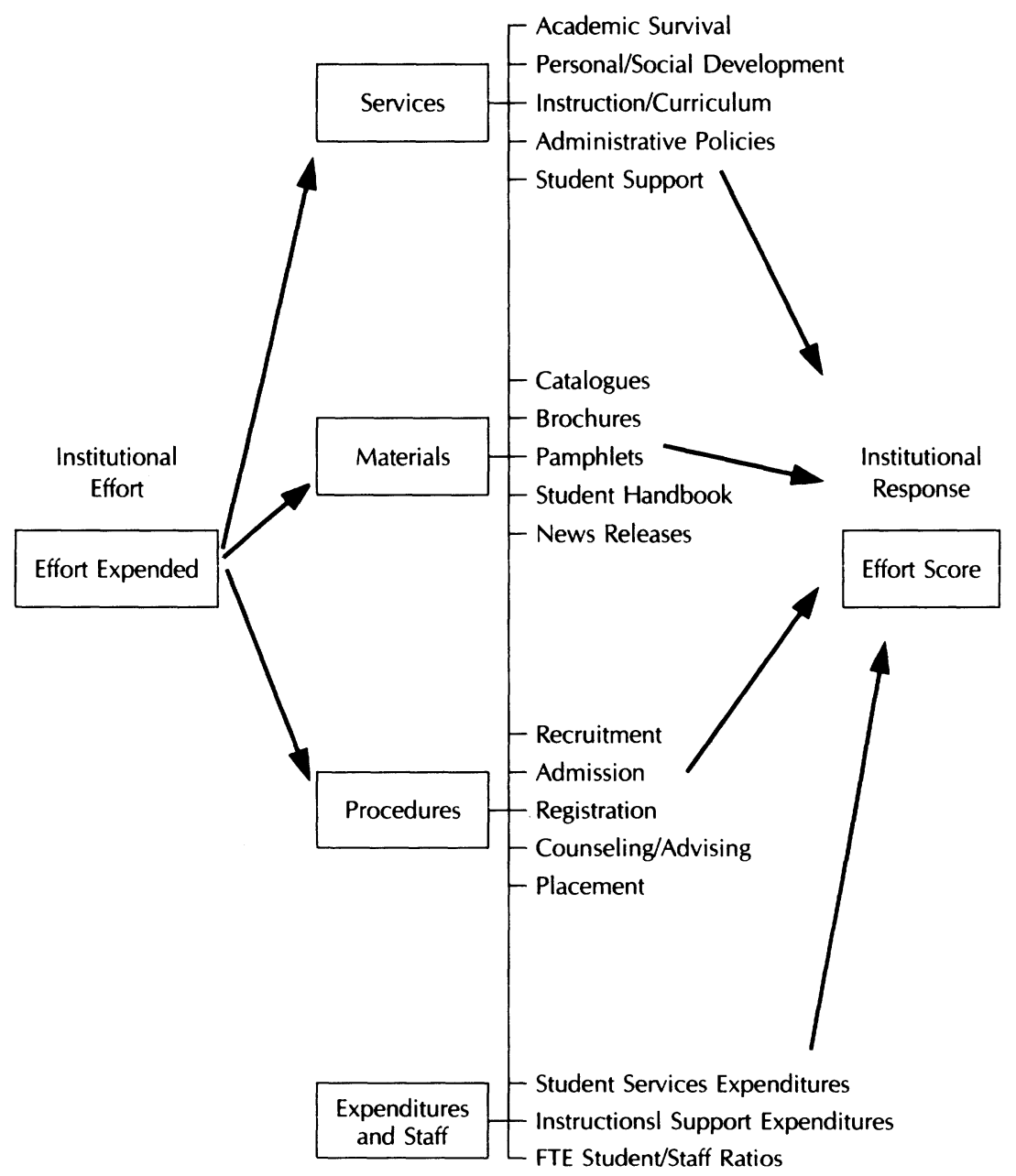

Figure 1 - Model of the Relationship of Factors Affecting Institutional Effort 
Figure 1 presents a model for measurement of effort based on examples of variables that could be utilized to assess the expenditure of institutional resources-policies, services, materials, dollars, and staff-to meet constituency needs. In this model, "effort" is the product of measurement in five dimensions:

- The content of institutional publications describing programs, services and policies.

- Institutional policies and procedures governing the workload of faculty, staff and administrators.

- Student and faculty perceptions of constituency educational needs and the current implementation level of programs and services.

- Institutional expenditures in cost-producing services (student services and instructional support) representative of actual institutional effort in meeting constituency needs.

- The ratio of full-time equivalent (FTE) students to full-time equivalent staff. Shown below are dimensions and specific indicators of institutional effort which can be used to measure productivity in each dimension:

Content of institutional publications:

- College catalogue.

- Academic program brochures.

- Service description brochures.

- Institutional operating budget.

- Institutional research reports

- Published long-term and short-term planning documents.

- Advertising and marketing documents.

- Student handbook.

- News and public relations releases.

- Program review summary reports.

Institutional policies and procedures governing workload:

- Board of trustees policy manual.

- Staff personnel manual.

- Written job descriptions.

- Committee guidelines and procedures (curriculum, marketing and recruiting, finance, etc.

- Faculty and staff workload policies.

- Collective bargaining contract.

- Program development guidelines.

- Counseling and advisory guidelines.

Student and faculty perceptions of constituency needs and program/service implementation:

- Academic survival.

- Personal/social development.

- Instructional/curricular patterns.

- Administrative policies.

- Student support. 
Institutional expenditures for cost-producing services:

- Student services expenditures.

- Socio-cultural development.

- Counseling and special guidance.

- Financial aid and placement.

- Auxiliary services.

- Student activities.

- Student recruitment.

- Admissions.

- Student records.

- Health and medical services.

Instructional support expenditures:

- Library services.

- Museums and galleries.

- Educational media services.

- Instructional administration.

- Instructional facility rental.

Ratio of full-time equivalent students to full-time equivalent staff:

- Student/counselor ratio.

- Student/faculty ratio.

- Student/support staff ratio.

As the first dimension in the effort model, the content of institutional publications describes the array of programs, senvices and activities provided in relationship to constituency needs. Publications such as the college catalogue, brochures, pamphlets, the student handbook, and a sample of news releases can be examined and translated into an effort score. Publication content would contribute to a high effort score when:

- consistency is demonstrated between constituency needs for services and the services actually provided;

- institutional sensitivity is apparent with respect to the educational needs of all ages of learners;

- freedom from bias is exhibited with regard to services rendered to specific race, age and gender groups.

Written policies and procedures descriptive of institutional practices regulating the workload and responsibilities of staff directed to assessment of constituency needs, marketing and recruitment, program and service development, and counseling and advisement constitute the second dimension which can be quantified and assigned an effort score as part of the model. Institutional policy and procedures manuals can be reviewed, job descriptions can be examined, and staff can be interviewed to determine the allocation of time and responsibility to the tasks of needs assessment and program development. The absence of written policies defining staff roles and responsibilities for needs assessment and program development would contribute to a low index of effort by the institution in providing programs and services which meet constituency needs.

A third dimension integral to the measurement of institutional effort is based upon student and faculty perceptions of constituency needs and program implementation. Instruments similar to those used by Mangano and Corrado in a 1979 survey of community college adult learner needs can be designed to identify 
educational needs and programmatic responses in five areas of college endeavor: academic survival, personal/social development, instructional/curricular patterns, administrative policies, and student support. An effort score can be calculated through determination of the extent to which "student need" and "program implementation" scores coincide in each activity dimension.

Institutional expenditures for cost-producing services is a fourth dimension necessary for consideration in assessment of institutional effort. Student services and instructional support comprise major cost-producing services in community colleges that contribute by effort to bridging the gulf between student needs and academic achievement. Student services activities include the following: student services administration, social/cultural development, counseling and special guidance, student activities, financial aid and placement, auxiliary services, student recruitmemt, admissions, student records, and student health and medical services. Instructional support includes: library services, museums and galleries, educational media services, instructional administration and support, and instructional facility rental. The percentage of the general fund spent on cost-producing student senvices and instructional support that directly contribute to satisfaction of constituency needs can be considered as an index of college commitment, thus comprising the basis for conversion into an effort score.

The final dimension of the effort model is the ratio of FTEstudents to staff. Analysis of ratios is in three categories:

- FTE students per FTE employee in student services and instructional support.

- Student/counselor ratio.

- Student/faculty ratio (class size) can be undertaken to determine institutional commitment to constituency needs.

For the purpose of analysis, it can be assumed that the lower the ratio of FTE students to staff, the greater the level of institutional effort in serving constiutuency needs.

\section{Assessing Institutional Effort}

To determine whether or not the effort concept can be implemented with any degree of precision in community colleges, a pilot test is necessary using data routinely available from institutions and state agencies. What follows is an illustration of the way in which the model can be used to quantify college effort based on instrumentation in four Michigan community colleges with differential serviceregion characteristics in the fall of 1985 . Service region differentiation is important because environmental factors can vary in impact for institutions engaged in service to constituency needs.

The four colleges participating in the pilot test of the instrumentation were differentiated according to location (rural versus urban), origin (establishment as a junior college versus establishment as a comprehensive community college), size (small versus large), administrative structure (centralized versus decentralized), facilities (fixed versus flexible space), and program/service mix (comprehensive versus concentrated programs). One characteristic was common to all of the colleges: changing demographics pointed to older learners as a population subgroup requiring substantial attention from Michigan community colleges in the next decade. Conditions of growth in the number of older learners as well as changing patterns of supply and demand in the labor market will combine to 
make older learners an important enrollment market for community colleges; therefore, older learners were selected as the reference group for assessment of college effort in each of the four institutions.

PHASE ONE: Collection and analysis of data describing: (1) college service region characteristics, including size and age group distribution of the population, economic climate, labor market conditions, and public policy conditions, and (2) institutional characteristics, including date of establishment, location, program/service mix, enrollment, student mix by age group, organizational structure, major sources of revenue, tuition pricing, student recruitment practices, FTE student to staff ratios, and expenditures for student services and instructional support services.

PHASE TWO: Surveys of currently enrolled students $(N=160)$ and faculty, administrators, and trustees $(N=39)$ in the four pilot institutions were used to determine perceptions of: (1) older student needs for postsecondary programs and services, and (2) availability of institutional programs and services to meet older student needs related to academic survival skills, personal/social development, instructional/curricular priorities, administrative policies, and student support services.

PHASE THREE: Secondary measurement of institutional effort in responding to older student needs through: (1) examination of documents common to all institutions describing the range of programs and services provided to older students in the college catalogue, current academic schedule, student handbook, college calendar, student recruitment schedule, self-study reports, and written goals and objectives, and (2) analysis of student utilization rates of support services.

PHASE FOUR: Computation of an effort score for each pilot institution through assignment of points for college performance in meeting older student needs based on information collected in phases one through three.

Scoring Institutional Effort. Total effort for each pilot institution was defined as one hundred percent based on a combination of multiple measurement units with each unit presumed to be a fraction of the total effort on a continuum of zero to one hundred percent. For each institution, trustee, faculty, and administrator responses to a 125-item survey instrument measuring older student needs and the availability of programs and services (academic survival, personal/social development, instructional/curricular, administrative policies, and student support) were quantified with a maximum allowable twenty points. College documents (catalogue, student handbook, academic schedule, etc.) were examined and a maximum allowable twenty points were assigned based on affirmative responses to thirteen questions listed below:

- In the table of contents, glossary of terms, or index of the catalogue, is there reference made to senior citizens, or older learners?

- Are there pictures of older learners used in (a) the catalogue, (b) brochures, (c) pamphlets, (d) the student handbook, or (e) other promotional materials?

- Is there reference to lifelong learning in the mission statement?

- Are goal statements or statements of purpose age-specific?

- Is there reference made in printed materials to student clubs, organizations, or meeting places for older learners?

- Do admissions criteria and classifications mention senior citizens as a category? 
- Under tuition costs, are rates for senior citizens spelled out?

- Does the printed nondiscrimination policy include age?

- Under student personnel services, is there a listing for an office of an individual assigned to address the concerns of older learners?

- Does the college distribute publications designed to recruit older learners?

- Are there news released or feature articles promoting older learners as students?

- Are admissions forms free of age-specific questions?

- Are there printed materials sensitizing administrators and instructional staff to the learning needs of older students?

Institutional policies and procedures governing workload were converted into an effort score with a maximum allowable thirty points based on affirmative responses to twenty-one questions as shown below:

- Do recruitment personnel visit senior centers, senior high-rise apartment buildings, meal sites, and senior citizen clubs for the purpose of obtaining students?

- Are there older persons as recruiters on the payroll or as volunteer employees of the college?

- Are recruitment officials trained to recruit older learners?

- When filling out admissions forms, are older learners advised to skip agespecific information?

- Has one person been assigned to help cut red tape: assist, and walk through the admissions procedure with the older learners?

- Are there procedures to ease the entry/reentry process for older learners?

- Are admissions procedures free from testing for older learners?

- Can older learners register by mail or phone?

- Is there an orientation session especially for older learners?

- Are courses held in senior citizen centers, senior high-rise apartment buildings, meal sites, or senior citizens' clubs?

- Are student services open and available evenings and weekends?

- Is there a counselor assigned to older learners?

- In the college public relations effort, is there emphasis on promoting the college as a "comfortable" and enjoyable place to learn?

- Is there in-service training for college personnel about the special needs of older learners?

- Are there procedures for assessing, and granting credit for prior learning?

- Is there job or community-service placement for older learners?

- Is there a college-sponsored social club for older learners?

- Are courses offered in brown-bag, one-day workshop, mini-series or other nontraditional formats for academic partial credit?

- Is there an older person's advisory council on campus?

- Has information about aging been integrated into the curriculum?

- Are there systematic and well-organized research efforts made to determine learner needs?

When placed on a scale numbering one to seventy points, the combination of services, materials and policies and procedures served as a partial index of effort. The remaining two indices, institutional expenditures for student services, and instructional support services and Full-Time Equivalent student/staff ratios, were 
quantified on the basis of examination of college budget materials and combined with the other indices to produce a total effort score for each pilot institution.

Analysis of Results. Analysis of the data revealed no differences by institutional type (rural versus urban) relative to the effort expanded to serve older student needs evident in the content of college publications, written policies and procedures, and the types of services offered. One urban community college and one rural community college expended the greatest amount of effort toward satisfaction of older learner needs. Although these colleges differed in size, administrative structure, facilities design, and student characteristics, they did share one characteristic in common. That was the existence of a marketing plan designed to promote a high level of community awareness and to increase the number of constituencies served. Data collected from pilot college trustees, administrators, and faculty relative to their perceptions of the current implementation of programs, services and policies to meet older-student needs exhibited a similar pattern of non-consistency among institutions. One urban college and one rural college appeared to be expending the most effort for each facet of need (academic survival, personal/social development, instructional patterns, administrative policies, and student services) with the greatest effort expended on needs related to instructional patterns for older students. Statistically significant differences were found among the four institutions regarding perceptions of program and service implementation to provide for older student needs related to administrative policies and student support services. These differences may, in part, reflect differential institutional priorities, staffing patterns, revenue patterns, and perceptions of the importance of education for older learners.

\section{Conclusions and Implications}

This study demonstrates that it is possible to measure productivity in community colleges using the concept of an effort score based on a five-dimension model. The study also demonstrates that institutions do not perform in predictable ways determined by their characteristics (location, age, origin, size, administrative structure, etc.) with regard to institutional effort in serving constituency needs. For example, although it would be expected that institutions experiencing a shift in the service region population to older age groups would modify their program/ service mix to improve service to these groups, the evidence examined does not support this conclusion. Instead, administrators with vision and commitment to expansion of opportunity for nontraditional learners appear to make the greatest difference with respect to institutional outreach to older students. College effort needs to be carefully examined with the idea of reordering priorities if institutions are to attract resources based on evidence of service to constituency needs.

Measuring institutional productivity by the concept of "effort" has considerable potential. For example, the effort concept could be used externally as a method of gaining legislative or foundation support for college programs. It could be used internally as part of the board of trustee self-evaluation procedures, part of a yearly evaluation of the performance of the president, an instrument for evaluating faculty and staff performance, and an index for assessing the effectiveness of activities, services, programs, and functions. Any single academic or administrative unit in a community college could include as a part of its formative and summative evaluation process the concept of measuring institutional effort.

The effort-score concept provides a flexible approach for assessment of productivity in community colleges that is more in keeping with the program and service 
objectives of the community college and the educational needs and goals of the constituencies it serves. Administrators using this concept should be able to develop and advance productivity arguments that qualify the institution for new resources beyond those that adhere to traditional finance formulas.

\section{References}

Lenning, O. T. (1978, May 22). A conceptual framework for identifying and assessing needs in postsecondary education. Paper presented at the Association for Institutional Research, Houston, Texas.

Mangano, J. \& Corrado, T. (1979, November). Reentry adult student project: Dissemination packet. Albany, New York: State University of New York.

Michigan State Board of Education. (1986, March). Michigan community colleges 1984-85 activity classification structure (ACS) data book. Lansing, Michigan: Higher Education Management Services.

Priest, B. \& Pickelman, J. (1976). Increasing productivity in community college: An action-oriented approach. Washington, D.C.: American Association of Community and Junior Colleges.

Robinson, J. \& Shaver, P. (1969). Measures of social psychological attitudes. Ann Arbor, Michigan: The University of Michigan, Survey Research Center.

Shaw, M. \& Wright, Jr. (1967). Scales for the measurement of attitudes. New York, New York: McGraw-Hill.

Carol Parker Thompson is Instructor, Muskegon Community College, Muskegon, Michigan.

Richard L. Alfred is Associate Professor and Program Chair, Program in Higher and Adult Continuing Education, School of Education, The University of Michigan, Ann Arbor, Michigan.

Malcolm Lowther is Professor, School of Education, The University of Michigan, Ann Arbor, Michigan. 